\title{
\begin{tabular}{|l} 
Sustainable Business \\
$\mid$ International Journal
\end{tabular}
}

JANEIRO DE 2016- ISSN 1807-5908

\section{Internacionalização De Pequenos Negócios E Imigração: Uma Investigação Sobre Negócios Brasileiros Na Cidade De Orlando - EUA}

\author{
Eduardo Picanço Cruz \\ Doutorado em Engenharia Química pela Universidade Federal do Rio de Janeiro. \\ Professor Adjunto IV do Departamento de Empreendedorismo e Gestão - STE da \\ Universidade Federal Fluminense. \\ epicanco@id.uff.br
}

Cesar Ramos Barreto

Doutorado em Antropologia pela Universidade Federal Fluminense.

Professor associado da Universidade Federal Fluminense.

crbarr@gmail.com

\begin{abstract}
Resumo: Os estudos de internacionalização de negócios e empreendedorismo internacional têm crescido muito nos últimos anos, na mesma proporção o esforço da academia para explicar a realidade e dar suporte teórico aos 'aventureiros' que buscam nos mercados exteriores novas oportunidades também pode ser notada nos congressos de gestão e revistas científicas. Mas todos esses trabalhos têm como ponto de partida as teorias que identificam razões econômicas ou comportais para essa empreitada no exterior. Uma realidade observada em várias cidades do mundo, dá conta de que existe uma quantidade de empresários brasileiros vivendo regularmente em diversos países com propósitos distintos e, principalmente, razões específicas para o processo de internacionalização. O presente artigo destaca os principais pontos de uma pesquisa básica realizada entre os anos de 2012 a 2014 com o apoio da FAPERJ para descrever o perfil dos empreendedores brasileiros no exterior. O estudo indicou fortes indícios de um modelo de internacionalização ainda não descrito que entende o processo muito mais através de aspectos pessoais do que empresariais.
\end{abstract}

Palavras-chave: internacionalização de negócios, empreendedorismo internacional, pequenas e médias empresas.

\begin{abstract}
The studies about business internationalization and international entrepreneurship have grown in recent years, at the same time academy's efforts to explain this reality and give theoretical support to the 'adventurers' seeking new business opportunities abroad can also be noted in management conferences and scientific journals. But all these papers take as their starting point some theories that ground the internationalization process in economic or behavioral factors. However a reality observed in cities across the world, realize that there are
\end{abstract}


a number of Brazilian businessmen regularly living in different countries with different purposes and mainly some specific reasons for the internationalization process. The present paper highlights the main points of a basic research conducted among 2012-2014, support by FAPERJ in order to describe the profile of Brazilian entrepreneurs abroad, specifically in Orlando - USA. The study showed an internationalization model based in personal aspects.

Keywords: business internationalization, international entrepreneurship, small and medium ventures.

\section{Introdução}

A depreender-se de dados provenientes das mais variadas fontes - dos artigos acadêmicos às reportagens dos periódicos leigos, passando pelos editoriais dos jornais econômicos - podemos afirmar que as iniciativas empresariais brasileiras no cenário mundial começam a adquirir expressividade. Todavia, por ser um quadro em elaboração, a imagem que se afigura ainda é pouco nítida e carece de delimitações. Conquanto possamos dispor de dados oficiais precisos sobre exportações e negócios ingressantes na disputa por mercados internacionais, pouco ainda se sabe sobre a movimentação e sobre os investimentos de brasileiros no exterior.

Em geral, a literatura acadêmica especializada, costuma abordar a temática Internacionalização de Negócios a partir da origem nacional de empresas, cujos produtos e mercadorias encontram oportunidades em mercados internacionais. A internacionalização é vista como uma expansão de negócios, uma vez satisfeito ou saturado o mercado nacional e vencidas as barreiras para a exportação e para a instalação de bases operacionais no exterior. O foco da abordagem geralmente está nos negócios e nos produtos, ficando as motivações dos próprios empresários e investidores para um segundo plano.

Contudo, no caso brasileiro, vimos observando um movimento de pessoas interessadas em certos modos de vida e de experiências no exterior que usam suas capacidades empresariais e gerenciais para se instalarem em outras terras. Muito além da imigração 


\section{$\mid$\begin{tabular}{|l} 
Sustainable Business \\
$\mid$ International Journal
\end{tabular}}

JANEIRO DE 2016- ISSN 1807-5908

aventureira e clandestina, temos encontrado brasileiros com elevada educação formal e alguma capacidade de investimento, que optam por desenvolver negócios no exterior, obedecem a impulsos - de certa forma, controlados - na direção de um novo modo de vida e emigram total ou parcialmente com suas famílias.

Há pouco mais de dois anos, os autores deste artigo iniciaram uma pesquisa básica sobre pequenos e médios negócios brasileiros instalados na cidade de Orlando, Florida, EUA. A relevância das informações preliminares coletadas ainda em território brasileiro nos levaram àquela cidade, onde iniciamos um processo de coleta de dados primários. A pesquisa no momento encontra-se em fase de expansão para Pompano Beach e Miami, também na Florida, com projetos de avanço para a cidade de Boston e arredores, onde há uma grande concentração de cidadãos e negócios brasileiros. Este artigo, que tem caráter exploratório e descritivo, aborda condições, desenvolvimentos e perfis de pequenos e médios empreendedores brasileiros no exterior e se propõe alcançar dois objetivos; um principal e dominante e, outro, acessório. O primeiro, descrever e discutir comparativamente dados relevantes da pesquisa in loco na cidade de Orlando e, o segundo, sugerir um novo modelo de abordagem no campo da Internacionalização de Negócios - que inclui movimentos migratórios - a ser aprofundado em outro trabalho.

\section{Dados Preliminares}

"Não há um número preciso sobre quantos empresários imigrantes são brasileiros", esta é a afirmação da reportagem do Gazeta Brazilian News (Raguzo, 2012). É a mesma informação se ouviu várias vezes durante a pesquisa de campo, mas que diz respeito a um fenômeno que começa a se afigurar como relevante para a elucidação dos movimentos 


\section{Sustainable Business International Journal}

JANEIRO DE 2016- ISSN 1807-5908

migratórios contemporâneos e para a economia e a empregabilidade em território americano. Ainda segundo a mesma reportagem, mais de 236 mil empregos são gerados por empresas estrangeiras no sul da Florida, região que abriga 45\% dos negócios estrangeiros nos EUA. Deste contingente, uma parte considerável - e ainda por contabilizar - constitui-se de negócios brasileiros.

O impacto dos investimentos dos empresários brasileiros emigrantes na economia norte-americana ainda está por ser desvendado. Dados do Banco Central do Brasil - BACEN (2014) demonstram que o crescimento médio do investimento brasileiro nos EUA aumentou, em média 6,67\% ao ano, chegando a casa dos 14 milhões de dólares em 2013. Todavia, não discrimina valores sobre quanto desse montante é realizado por pessoas que deixaram o país com recursos para investir nos EUA e os que investem diretamente do Brasil sem sair do país. Porém, os dados do BACEN não contabilizam os investimentos de brasileiros decorrentes da acumulação de resultados de negócios iniciados e desenvolvidos na economia norteamericana, posto que esses resultados pertencem à própria economia norte-americana.

O Relatório Final da Comissão Parlamentar Mista de Inquérito da Imigração do Governo Brasileiro (2006, p. 25) dá conta de que entre 1,8 e 2 milhões de brasileiros viviam nos EUA em 2006, quase a metade do total de brasileiros imigrantes pelo mundo todo. Reportagem da revista Veja (1996) informa que a comunidade brasileira na Florida cresceu $20 \%$ ao ano, entre 1990 e 1996, mais do que qualquer metrópole brasileira no período, e estimou que viviam 200.000 brasileiros naquele estado, em 1996. Segundo reportagem da revista IstoÉ (2014), haviam 250.000 brasileiros morando na Florida em 2014.

O Corpo Consular brasileiro nos EUA registrou 112.252 eleitores brasileiros cadastrados naquele país em 2014, sendo o Consulado Geral de Miami (residentes da Florida, 


\section{Sustainable Business International Journal}

JANEIRO DE 2016- ISSN 1807-5908

Porto Rico e Ilhas Virgens) responsável pela emissão de 22.294 documentos eleitorais. Esse número é superior ao da Itália (21.168), da Alemanha (18.113) e de todos os países que conhecem imigração brasileira, exceto Japão (37.638) e Portugal (30.910). (Barbosa, 2014)

Devido ao grande número de situações migratórias irregulares, provavelmente jamais saberemos o exato tamanho da "diáspora brasileira", exceto no Japão, país que controla o seu quantitativo de imigrantes através de contratos de trabalho (República Federativa do Brasil, 2006). Todavia, na Florida, o volume perceptível e crescente de negócios brasileiros e de empregos providos por eles têm estimulado esforços na direção da quantificação, bem como da ampliação do volume de informações sobre condições mercadológicas e competitivas.

\section{Empreendedorismo Internacional}

Iniciamos a pesquisa bibliografia estudando os principais autores brasileiros que já haviam estudado o assunto. Dessa forma, usamos dois instrumentos bibliométricos locais: a plataforma Lattes do Conselho Nacional de Desenvolvimento Científico e Tecnológico CNPq e a base de artigos da Associação Nacional de Associação Nacional de Pós-Graduação e Pesquisa em Administração - ANPAD. Esse estudo bibliométrico nos indicou alguns autores que nos levou a perceber dois aspectos relevantes para o estudo: a identificação dos principais temas sobre internacionalização e o mapeamento de autores internacionais relevantes. A revisão bibliográfica de Dalmoro (2008) apontou uma série de estudos acerca do tema, destacando trabalhos sobre o desenvolvimento das teorias de empreendedorismo internacional, a relação entre inovação e internacionalização e o surgimento das Born Globals. Esse estudo nos ajudou a elaborar o questionário inicial da presente pesquisa e, em futuros artigos, será a base conceitual para uma análise crítica das teorias de internacionalização. 


\section{Sustainable Business International Journal}

JANEIRO DE 2016- ISSN 1807-5908

É possível identificar considerações sobre internacionalização desde a década de 1960, com estudos sobre o processo de internacionalização focado no âmbito da teoria do comportamento organizacional (Hilal \& Hemais, 2001). Esse processo de internacionalização, desde então, é encarado como um processo racional fundamentado no crescimento e pode estar focado tanto na empresa em si, que esgota suas posições no país de origem e busca oportunidades nos mercados externos, ou focado na figura do empreendedor, que vislumbra a possibilidade de vantagens ou ganhos através de redes de relacionamento criadas ou possibilidades de explorar e desenvolver novos mercados. Em ambos os casos, há significativos esforços da academia no sentido de explicar os processos de internacionalização e criar modelos que venham a ser base para que os próximos empreendedores minimizem seus riscos de entrada.

- Teorias de Expansão: A exportação é a opção mais simples para as pequenas empresas se internacionalizem, mas oferece pouco controle sobre as atividades internacionais, gerando um desempenho abaixo do ideal (Crick \& Jones, 2000). Porém, estudos na área envolvem outras abordagens e aspectos como a cultura inovadora que as empresas adotam em mercados internacionais (Knight \& Cavusgil, 2004), ou laços sociais que podem ajudar a identificar oportunidades no exterior (Ellis, 2011). Ainda neste enfoque, de acordo com Holland (1999), o processo de internacionalização de uma empresa apresenta basicamente 3 etapas: exportações; abertura de escritório no exterior; e deslocamento da estrutura de produção.

- Teorias Econômicas: De acordo com a teoria do poder de mercado, grandes empresas monopolistas ou oligopolistas usam sua estrutura para criar barreiras de mercado. Essa estratégia permite um fortalecimento tal que a internacionalização seria uma ação mais 


\section{$\mid$\begin{tabular}{|l} 
Sustainable Business \\
|| International Journal
\end{tabular}}

JANEIRO DE 2016- ISSN 1807-5908

facilmente executada (Hymer, 1960). Esta teoria da internacionalização propõe às empresas transnacionais que entrem no mercado externo através de investimentos diretos, ao invés de licenciamento, quando tiverem vantagens diferenciais com relação a outras firmas (Coase, 1937). Uma outra versão - a teoria do paradigma eclético - a teoria econômica envolve a internacionalização da produção e busca um diferencial sobre os competidores, ao invés de ceder seus direitos a outras firmas (Dunning, 1977);

- Teorias Comportamentais: O modelo de Uppsala é aquele em que processo de internacionalização se dá de forma gradual, orientado pela proximidade psíquica, a partir do acúmulo de conhecimentos que o empreendedor faz do mercado externo (Johanson \& Vahlne, 1977). Esse modelo vem sendo dividido em duas vertentes: a primeira seria a do modelo tradicional que se baseia nas experiências de internacionalização através das menores distâncias psíquicas, pois apresentariam menos diferenças culturais e linguísticas, por exemplo. A segunda vertente inclui a internacionalização em networks, que envolvem aqueles negócios cujo processo se dá através das redes de relacionamento criadas que auxiliam e minimizam os riscos, servindo de apoio a nova empresa (Johanson e Mattson, 1986). Nesse sentido, seriam esses laços de relacionamento e interações sociais entre empresários, não necessariamente a distância psíquica, que determinariam o sucesso do processo de internacionalização. Na teoria do empreendedorismo internacional de McDougall e Oviatt (2000) temos um estudo mais abrangente envolvendo aspectos fundamentais como a gestão comercial, a vantagem competitiva, preço e recursos em outro país; além da combinação de inovação, pro atividade e aversão ao risco. Esse autores destacam que existem 4 tipos de empreendimentos internacionais: startups de importação e exportação; comerciantes multinacionais; startup geograficamente focada e startup global. Indicam ainda que os 


\section{Sustainable Business International Journal}

JANEIRO DE 2016- ISSN 1807-5908

empreendimentos têm diferentes vantagens e velocidades para a internacionalização, determinadas de acordo com 4 forças: viabilidade, motivação, mediação e moderação. Assim, o conceito está direcionado à análise que os empreendedores têm em relação a uma oportunidade de expansão internacional e como as exploram.

- Teoria das Born Globals: McDougall e Oviatt (1994) analisaram 24 estudos de empresas desafiadoras das teorias tradicionais de empreendedorismo, uma vez que possuíam características diferentes de internacionalização comparada às multinacionais e empresas já inseridas e firmadas no mercado local. De acordo com Dib (2008) born globals são empresas fundadas após 1990, com atividades internacionais entre 2 e 15 anos após a fundação, com porcentagem do faturamento proveniente de operações no exterior (entre 5\% e 75\%) e abrangência de mercados (dois ou mais mercados internacionais).

- Teoria da Adaptação Cultural: Adaptação transcultural é definida como o grau de conforto psicológico nos diferentes aspectos que envolvem a vida do imigrante no país de destino (Black, 1988). Esse autor analisa a adaptação baseado em três aspectos principais: grau, modo e facetas. Em relação ao grau de adaptação são reveladas quatro etapas, apresentadas pela "Curva-U", que inicia-se com a fase do encantamento e vislumbre devido as novidades do novo país, em seguida passando pela fase de frustração e hostilidade resultado dos conflitos culturais, posteriormente a fase de redução do estresse por causa da maior habilidade na língua e locomoção, finalizando no ajustamento quando o indivíduo apresenta capacidade de viver no ambiente sem angústia e com eficácia (Black, 1988).

Fundamental para o enriquecimento teórico da Internacionalização de Negócios, o estudo sumarizado acima resumido não nos supriu inteiramente para os propósitos deste artigo. Será provavelmente necessária uma investigação adicional no campo da teoria das 


\section{Sustainable Business \\ International Journal}

JANEIRO DE 2016- ISSN 1807-5908

migrações humanas, na qual possamos inserir um viés empreendedor, propondo um novo modelo de internacionalização.

\section{Metodologia}

Existem diversas classificações para as pesquisas científicas, que normalmente adotam elementos próprios para categorização. Especificamente, na pesquisa em tela, ficamos convencidos de que se trata de uma pesquisa básica, principalmente, ao adotarmos o conceito do Frascati Manual, editado e mantido pela Organization for Economic Co-operation and Development - OECD. O manual descreve a pesquisa básica como um "experimental or theoretical work undertaken primarily to acquire new knowledge of the underlying foundations of phenomena and observable facts, without any particular application or use in view" (OECD, 2002, p.77). Lembrando que o objetivo dominante deste artigo é expor o resultado de uma pesquisa básica, isso significa que o texto tem propósito descritivo e exploratório. Nesse sentido, após o detalhamento da metodologia da pesquisa, passaremos à descrição dos resultados observados, visando, secundariamente, a identificação de hipóteses a serem exploradas em trabalhos futuros.

A primeira fase do projeto de pesquisa em tela envolveu a coleta de dados e informações apresentados nesse artigo. Principalmente, objetiva-se apresentar elementos relativos ao tamanho dos negócios, número de empregados, origem e perfil de mão de obra, escolaridade, nível de adaptação da qualidade em produtos, atendimento e serviços agregados. O mapeamento inicial das empresas foi realizado a partir de sites mantidos por brasileiros na cidade e de jornais brasileiros locais. Essa sondagem inicial evidenciou um número expressivo de negócios, mas não a população de empresas, fator que estes pesquisadores 


\section{Sustainable Business International Journal}

JANEIRO DE 2016- ISSN 1807-5908

alimentaram a esperança de obter na primeira visita, mas que hoje, após quatro visitas, ainda não foi conseguido. Nesse primeiro levantamento foram identificadas 266 empresas e instituições distribuídas, predominantemente, nas áreas de: Alimentação e Lazer, Varejo, Saúde e Bem-Estar, Lar e Construção, Escolas e Cursos, Igrejas e Associações.

Em seguida, o grupo pesquisador planejou e organizou os instrumentos de coleta de dados. Em face da natureza exploratória da primeira fase, optou-se por um questionário estruturado, eventualmente associado a entrevistas semiestruturadas, evitando-se um questionamento invasivo em relação aos respondentes. $\mathrm{O}$ primeiro instrumento visou à obtenção de dados objetivos e quantificados e o segundo conseguiu prover algumas inferências etnográficas da população, mas que ainda requerem aprofundamento. $\mathrm{O}$ questionário foi dividido em campos temáticos, sobretudo ligados à gestão de negócios atividade básica, gestão financeira, marketing, recursos humanos, compras e estoque - mas incluiu também campos de dados que forneceram informações pessoais sobre os empresários, tais como atitudes e características gerenciais, faixa etária, escolaridade, tempo de migração e outros.

Previamente, foram contatados dois empresários - estabelecidos na cidade há mais de vinte anos - que se dispuseram a contribuir como informantes, a quem estes autores muito devem pelas indicações e apresentações de potenciais respondentes, táticas de aproximação e racionalização de deslocamentos. Além dos 2 empresários citados, foram ouvidos outros 10 empreendedores. Interessante destacar a desconfiança desses entrevistados quando os pesquisadores eram recebidos e o nítido medo de dar informações. Essa característica contrasta muito com os estudos de Baltar et al (2013) que conseguiram facilmente contato com 268 empresários argentinos na Espanha através de contato eletrônico. O link na internet 


\section{Sustainable Business International Journal}

JANEIRO DE 2016- ISSN 1807-5908

da pesquisa em tela ficou disponível por 1 ano e, mesmo depois de um massivo contato feito, não conseguimos mais do que 2 respostas. Por outro lado, a baixa produtividade do link digital não desanimou os pesquisadores, isso por que a formação antropológica de um dos coordenadores do projeto sugeriu, além do questionário, uma entrevista de profundidade com caráter etnográfico. As pesquisas foras gravadas com autorização dos empresários e ficaram guardadas nos arquivos do projeto.

A primeira impressão deixada na visita realizada em outubro de 2012 foi o baixo grau de associação entre os empresários, evidenciada pela dificuldade dos brasileiros em se organizarem em uma única classe de atividades ou mesmo como um grupo étnico - situação bem diferente daquelas percebidas entre os diversos grupos de imigrantes hispânicos na região, de modo geral. Existem associações brasileiras como uma Câmara de Comércio - que até hoje constitui a nossa principal referência - e alguns Clubes e Grupos de Profissionais. Todavia, operam de forma isolada, perdendo obviamente força política, econômica e social. Diferentemente do que parece acontecer na região de Boston, por exemplo - onde há indicadores de acentuada iniciativa coletiva e de organização étnica - , o empreendedorismo brasileiro em pequenos negócios na Florida se nos pareceu decorrente de iniciativas individuais e constituído por sujeitos dotadas de alto grau de confiança pessoal e pouco avessas ao risco

É notável a dependência da maioria dos negócios em relação ao turismo brasileiro. O apelo é tão forte que chegamos a encontrar lojas com nomes em português e bandeiras brasileiras estampadas nas vitrines, cujos donos eram argentinos ou indianos. Também já na primeira fase dos trabalhos, foi possível constatar a necessidade de um segmento teórico de pesquisa em Internacionalização de Negócios e/ou Empreendedorismo Internacional que 


\section{Sustainable Business International Journal}

JANEIRO DE 2016- ISSN 1807-5908

contemplasse diretamente a imigração. É, de fato, significativa na amostra pesquisada a presença de empresários que ali estavam devido à oportunidade de sair do Brasil. Tal motivação surgiu na pesquisa como maior e mais intensa do que o propósito puramente empresarial de ampliar o sucesso econômico de seus negócios no país de origem, como sugerem as teorias de internacionalização.

Em 2013, após tratamento dos dados inicialmente recolhidos, foi elaborado um segundo questionário, escoimado de questões que se revelaram desnecessárias a partir da fase exploratória, porém compatível com o primeiro para não comprometer a consolidação de dados quantitativos. Na segunda visita, realizada em novembro de 2013, o trabalho fluiu com mais facilidade devido a dois fatores: primeiro, a experiência acumulada pelos pesquisadores e, segundo, muito relevante e revelador, a superação da desconfiança, encontrada na primeira fase, por parte do empresariado local. Atribuímos a minimização da desconfiança a fatores como manutenção de contatos via correspondência eletrônica, divulgação de informações no site do projeto da pesquisa em tela e o próprio retorno dos pesquisadores, que passaram a ser conhecidos no meio social local, condição de confiabilidade característica do sistema de relações no povo brasileiro. ${ }^{1}$

Nessa segunda etapa, cerca de 28 empresários foram entrevistados. Os dados agrupados aos 12 primeiros questionários foram tratados e geraram algumas correlações. De posse dos dados compilados, iniciou-se uma série de debates no grupo de pesquisa que culminaram com a identificação da necessidade de mais uma fase de entrevistas. Esta, realizada em maio de 2014, incluiu entrevistas menos condicionadas por um questionário

\footnotetext{
${ }^{1}$ No intervalo entre a primeira e segunda visitas, os pesquisadores tentaram ampliar a coleta de informações através da internet, utilizando um modelo próprio para esse fim. O retorno foi, entretanto, pífio, mesmo dentre empresários já antes contatados e solicitados a responder a um questionário pela internet.
} 


\section{Sustainable Business International Journal}

JANEIRO DE 2016- ISSN 1807-5908

preestabelecido e atingiu apenas alguns empresários, preferencialmente aqueles com mais tempo nos EUA, com maior participação na organização da comunidade empresarial brasileira, bem como profissionais especializados em migração e aspectos fiscais e trabalhistas nos EUA. ${ }^{2}$

Enfim, foram feitas no total 40 entrevistas de profundidade com empresários o que gerou a seguinte questão: como validar a amostra? Recorremos a Atkinson e Flint (2001) para validação através da técnica de bola de neve. De acordo fontes secundárias e os próprios autores, o método oferece uma razoável abordagem para se chegar a populações ocultas, aliás, os pesquisadores ouviram diversas vezes ser esta a pergunta de U\$1.000.000,00: qual o numero de negócios brasileiros na Florida? A referida metodologia pressupõe que há uma ligação entre os membros da população dado pela característica de interesse, isto é, os membros da população são capazes de identificar outros membros da mesma - fato existente no estudo em tela. Por fim, a ideia é que o processo amostral termine quando se atinge uma estabilidade, ou seja, quando poucos novos contatos são acrescentados (Atkinson \& Flint, 2001). No estudo em tela, apesar de percebermos a existência de outros empresários na região, seja pelo tempo necessário para se fazer uma entrevista de profundidade ou pelo receio dos empresários em sugerirem novos contatos, consideramos que o número de 40 entrevistas (15\% do levantamento inicial de empresas via sites da internet) seria suficiente para fecharmos um primeiro quadro. Sabemos que a técnica pode gerar vieses, portanto, evitamos generalizar as conclusões do presente artigo.

\footnotetext{
${ }^{2}$ Uma quarta visita foi realizada em setembro de 2014, incluindo na agenda entrevista com o Cônsul Geral do Brasil em Miami. Contudo, dados obtidos nessa visita, através de entrevistas com empresários brasileiros em Pompano Beach e Miami, ainda estão sendo processados e não fazem parte deste artigo.
} 


\section{Sustainable Business International Journal}

JANEIRO DE 2016- ISSN 1807-5908

\section{Análise de Dados}

A amostra constituiu-se de empreendedores pessoas físicas em negócios de varejo, alimentação, serviços e jornalismo, predominando amplamente o primeiro tipo. Dados preliminares e pesquisa bibliográfica empreendida antes da primeira visita levaram os autores a formular a hipótese de existência de dois grupos distintos: um de menor faixa etária, formado por jovens empresários que teriam chegado aos EUA com formação superior completa e já empresários; o outro grupo seria supostamente formado por empresários mais velhos que teriam chegado aos EUA ainda na década de 80, firmaram-se como funcionários de outras empresas para depois empreenderem seus próprios negócios.

\section{Tabela 1: faixa etária}

\begin{tabular}{|l|c|}
\hline \multicolumn{1}{|c|}{ Intervalos } & $\%$ \\
\hline 21 a 30 anos & $7,4 \%$ \\
\hline 31 a 40 anos & $33,3 \%$ \\
\hline 41 a 50 anos & $18,5 \%$ \\
\hline 51 a 60 anos & $33,3 \%$ \\
\hline 61 a 70 anos & $3,7 \%$ \\
\hline De 71 a 80 anos & $3,7 \%$ \\
\hline
\end{tabular}

De fato, os dados obtidos permitem classificar os empresários em grupos como os mencionados acima. Todavia, uma vez correlacionados os dados de faixa etária com os integrantes dos grupos, a hipótese não se confirmou. A média de idade de ambos os grupos foi praticamente a mesma: 47 anos. Os desvios padrões também ficaram muito próximos.

A média de tempo de emigração do Brasil para os EUA da amostra é de 12 anos. O nível de educação formal da amostra é surpreendentemente alto, com pouco mais de $70 \%$ de empresários com formação superior completa e/ou pós-graduação. Não identificamos na amostra casos de escolaridade, nos graus referidos, obtidos nos EUA. Todavia, informações 


\section{Sustainable Business \\ International Journal}

JANEIRO DE 2016- ISSN 1807-5908

posteriores dão conta de que existem empresários brasileiros com educação formal obtida nos EUA, sobretudo, pós-graduação.

Figura 1: formação

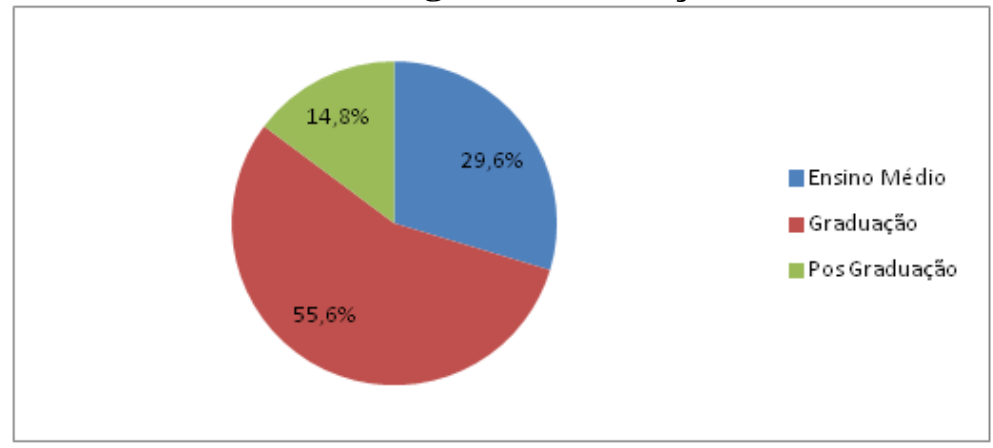

Outra hipótese antes formulada foi a de que haveria mais pessoas com maior educação formal dentre aqueles que têm menos tempo nos EUA. Porém, obtivemos os seguintes dados: correlação total entre a escolaridade e o tempo de emigração da amostra é de - 0,03, não há correlação entre essas variáveis; os indivíduos que chegaram aos EUA apenas com o ensino médio concluído estavam no país a 14,88 anos, em média, com desvio padrão em torno de 10 pontos; os que chegaram aos EUA com uma graduação concluída estavam no país a 10,87 anos, em média, com desvio padrão em torno de 7,5 pontos; e os que chegaram aos EUA com curso de pós-graduação concluído estavam no país a 17 anos, em média, com desvio padrão em torno de 14 pontos. Novamente, a hipótese não pode ser confirmada pelos dados da amostra, uma vez que não há correlação total entre escolaridade e tempo de emigração e o maior grau de escolaridade está dentre aqueles com mais tempo médio de emigração, embora com desvio padrão mais acentuado.

A correlação dos dados da amostra entre essas variáveis demonstra que os indivíduos já empresários estão dentre aqueles com menor tempo médio de emigração. Os chamados 


\section{Sustainable Business \\ International Journal}

JANEIRO DE 2016- ISSN 1807-5908

"aventureiros" (sem perspectiva de trabalho) estão dentre aqueles com maior tempo médio nos EUA.

Tabela 2: Como chegou aos EUA

\begin{tabular}{|l|c|}
\hline \multicolumn{1}{|c|}{ COMO } & Há quanto tempo nos EUA \\
\hline Já empresário & 8,4 anos em média \\
\hline Com emprego & 14,8 anos em média \\
\hline Sem perspectiva de trabalho & 15,5 anos em média \\
\hline
\end{tabular}

Devemos notar que a amostra é totalmente constituída de empresários atualmente, o que inclui os que chegaram aos EUA como empregados e os "aventureiros" que se tornaram empresários. Os dados corroboram a percepção pessoal de muitos dos entrevistados, que apontaram uma "nova geração" de pessoas chegando a cidade de Orlando como empresários, denotando uma certa mudança do perfil emigrante brasileiro do "aventureiro" para o “empreendedor".

Tabela 3: Ocupação no Brasil antes de emigrar

\begin{tabular}{|l|c|}
\hline Não trabalhava & $10,7 \%$ \\
\hline Empresário formal & $53,6 \%$ \\
\hline Funcionário Público & $7,1 \%$ \\
\hline Empresário informal & $3,6 \%$ \\
\hline Funcionário de empresa privada & $25,0 \%$ \\
\hline
\end{tabular}

Mais da metade $(53,6 \%)$ dos respondentes já era empresário formal no Brasil. Todavia, se extrairmos este contingente da amostra e verificarmos as suas ocupações quando chegaram aos EUA, veremos dados surpreendentes.

Tabela 4: Como chegaram aos EUA os respondentes que eram empresários no Brasil?

\begin{tabular}{|l|l|}
\hline Chegou aos EUA empresário & $56,0 \%$ \\
\hline Chegou com emprego informal & $13,0 \%$ \\
\hline Chegou sem perspectiva de trabalho & $31,0 \%$ \\
\hline
\end{tabular}




\section{Sustainable Business International Journal}

JANEIRO DE 2016- ISSN 1807-5908

A maior parte dos que já eram empresários no Brasil manteve essa condição nos EUA. Entretanto, cerca de $44 \%$ de ex-empresários no Brasil parece ter decidido enfrentar a vida nos EUA inicialmente sem essa condição, sendo elevado o percentual de "aventureiros" (sem perspectiva de trabalho). Notemos mais uma vez que, atualmente, todos são empresários.

Tornando ao total da amostra, verificamos as condições com que os atuais empresários chegaram aos EUA, em termos de ocupação.

Tabela 5: Perspectivas ao desembarcar nos EUA

\begin{tabular}{|l|c|}
\hline Sem perspectiva de trabalho & $44,4 \%$ \\
\hline Com emprego informal & $11,1 \%$ \\
\hline Já empresário & $37,0 \%$ \\
\hline Com emprego formal & $7,5 \%$ \\
\hline
\end{tabular}

Somente $37 \%$ dos empresários brasileiros atualmente estabelecidos em Orlando chegaram aos EUA já com tal condição.

A pergunta aberta "Por que Deixou o Brasil?" proporcionou um importante fator de elucidação sobre as condições e características dos empresários emigrantes brasileiros na cidade de Orlando. Distribuímos as respostas em 4 categorias:

1. Não querem mais o Brasil: 40,0\%. Foram classificadas nesta categoria as respostas do tipo "deixei o Brasil por causa da violência", "cansei, acho o Brasil inviável”, "queria melhorar a qualidade de vida da família" ou "melhor educação para os filhos". Os itens mais frequentes foram segurança, educação e saúde;

2. Ficaram encantados com os EUA: 21,0\%. Respostas de empresários que declararam ter decidido deixar o Brasil após uma viagem aos EUA, quando teriam ficado maravilhados com a infraestrutura e a ordem urbanas, o asseio, o equilíbrio entre tributação e justiça social e a educação formal. Cabe ressaltar que $56 \%$ dos 


\section{Sustainable Business International Journal}

JANEIRO DE 2016- ISSN 1807-5908

entrevistados informaram ter chegado aos EUA através da cidade de Orlando, evidenciando o encantamento exercido pela própria cidade sobre os brasileiros;

3. Oportunidades pessoais: $18,0 \%$. Categoria das respostas daqueles que deixaram o Brasil porque viram oportunidades para estudar (sobretudo, o idioma inglês), porque a presença de parentes morando nos EUA ofereciam oportunidades para novas experiências pessoais, porque encontraram saída para problemas pessoais no Brasil (sobretudo conjugais) e outras situações pessoais;

4. Oportunidades de negócios: 21,0\%. Respostas de entrevistados que declararam ter deixado o Brasil por causa de oportunidades de negócios para fins de expansão de mercado, através de franquia ou outra atividade comercial.

Apenas $21 \%$ dos atuais empresários em Orlando emigraram do Brasil para os EUA em busca de oportunidades de negócios. Para pesquisadores em busca de motivações econômicas para internacionalização de negócios, esse dado da pesquisa pode parecer decepcionante. Todavia, teve a propriedade de abrir uma enorme perspectiva para a inferência das motivações da migração silenciosa dos brasileiros nos últimos 30 anos, fenômeno que o Relatório Final da CPI da Imigração (2006) chamou de "diáspora brasileira".

E mais, orientou estes autores a buscar na literatura vigentes modelos sobre Internacionalização de Negócios e Empreendedorismo Internacional voltados para a direção da inclusão de motivações não econômicas para a internacionalização. Mesmo motivados por sentimentos pessoais de aversão ao Brasil ou de encantamento com outro país ou cidade, os movimentos migratórios que observamos são capazes de gerar consequências econômicas, expressas através de empregos gerados e de investimentos que afetam tantos a economia de destino quanto a de origem. Baltar et al (2013) dividiu suas respostas em apenas 2 grupos: 


\section{Sustainable Business International Journal}

JANEIRO DE 2016- ISSN 1807-5908

empreendedores motivados pela oportunidade e motivados pela necessidade. Se usássemos organização de dados análoga, acreditamos que os 3 primeiros padrões de resposta (não querem mais o Brasil, ficaram encantados com os EUA e oportunidades pessoais) se enquadram como motivados pela necessidade e o ultimo (oportunidade de negócios) seriam motivados pela oportunidade.

Em termos de tamanho dos negócios, os dados da amostra das empresas de brasileiros em Orlando estão distribuídas da seguinte maneira:

\section{Tabela 6: Tamanho do negócio nos EUA}

\begin{tabular}{|l|r|}
\hline Grande empresa & $3,7 \%$ \\
\hline Pequena empresa & $85,2 \%$ \\
\hline Empresa de médio porte & $11,1 \%$ \\
\hline
\end{tabular}

Em território nacional brasileiro, de acordo com o "Empresômetro" do Instituto Brasileiro de Planejamento Tributário - IBPT (2012) As empresas brasileiras são constituídas, em sua maior parte, na categoria de micro e pequeno porte, representando $85 \%$ do total. As empresas de médio e de grande portes representam somente $15 \%$ do total. Estes dados apresentam correlação perfeita com aqueles que obtivemos em Orlando. ${ }^{3}$

Para, principalmente, minimizar riscos, as teorias de empreendedorismo destacam a necessidade de que se conheça o mercado alvo. Nesse sentido, arguimos os empresários quanto aos conhecimentos prévios para a abertura do negócio.

Tabela 7: Conhecimento do mercado e do negócio

\begin{tabular}{|l|c|c|}
\hline & Conheciam o ramo de negócio? & Conheciam o mercado americano? \\
\hline SIM & $56 \%$ & $37 \%$ \\
\hline NÃO & $44 \%$ & $63 \%$ \\
\hline
\end{tabular}

\footnotetext{
${ }^{3}$ Cabe, entretanto, uma observação. O conceito de 'pequena empresa' nos EUA é geralmente reduzido àquelas que possuem uma arrecadação anual abaixo de 1 milhão de dólares. Tal como as micro empresas brasileiras, gozam de algum benefício fiscal e processual, mas sua classificação obedece a diferentes critérios.
} 


\section{Sustainable Business International Journal}

JANEIRO DE 2016- ISSN 1807-5908

Um estudo do SEBRAE (2007) feito nas 27 Unidades da Federação com 14.181 empresas, criadas entre 2003 e 2005, das quais 13.428 ativas e 753 extintas, apontou os fatores de sucesso para esses empreendedores. Dentre os resultados, "o bom conhecimento do mercado onde atua" estava entre as características de importância mais relevante ao empreendedor, no quesito habilidades gerenciais.

A forte incidência de respostas negativas ao conhecimento do ramo sugere um empresário com fraco perfil administrativo, movido por impulsos pessoais para a implementação do seu negócio e pouco avesso a riscos. Sugestão fortalecida quando identificamos que mais da metade dos respondentes alegou não conhecer as particularidades do mercado onde se propunha atuar.

Avaliamos também se os ramos de negócio dos empreendedores nos EUA eram os mesmos ou diferentes do que atuavam no Brasil. A questão inclui também os que não eram empresários no Brasil e separa aqueles que são empresários nos EUA e ainda mantém negócios no Brasil.

Tabela 8: Área de atuação no Brasil e nos EUA

\begin{tabular}{|c|c|c|}
\hline \multirow{2}{*}{$\begin{array}{l}\text { Respondentes em } \\
\text { geral }\end{array}$} & $\begin{array}{c}\text { Atuam em ramos DIFERENTES nos EUA do que } \\
\text { atuavam no Brasil }\end{array}$ & $67 \%$ \\
\hline & $\begin{array}{l}\text { Atuam no MESMO ramo de negócios nos EUA do } \\
\text { que atuavam no Brasil }\end{array}$ & $33 \%$ \\
\hline \multirow{2}{*}{$\begin{array}{l}\text { Só os que eram } \\
\text { empresários no } \\
\text { Brasil }\end{array}$} & $\begin{array}{c}\text { Atuam em ramos DIFERENTES nos EUA do que } \\
\text { atuavam no Brasil }\end{array}$ & $69 \%$ \\
\hline & $\begin{array}{l}\text { Atuam no MESMO ramo de negócios nos EUA do } \\
\text { que atuavam no Brasil }\end{array}$ & $31 \%$ \\
\hline \multirow{2}{*}{$\begin{array}{c}\text { Só os que } \\
\text { mantiveram seus } \\
\text { negócios no } \\
\text { Brasil }\end{array}$} & $\begin{array}{l}\text { Atuam em ramos DIFERENTES nos EUA do que } \\
\text { atuavam no Brasil }\end{array}$ & $57 \%$ \\
\hline & $\begin{array}{l}\text { Atuam no MESMO ramo de negócios nos EUA do } \\
\text { que atuavam no Brasil }\end{array}$ & $43 \%$ \\
\hline
\end{tabular}




\section{Sustainable Business International Journal}

JANEIRO DE 2016- ISSN 1807-5908

A maior parte da amostra de atuais empresários brasileiros em Orlando atua em negócios diferentes, não importa o corte que se faça. Isso pode sinalizar 3 alternativas para as escolhas dos empresários: $i$, os empresários percebem que sua área de atuação original já está bem atendida nos EUA; $i$, os empresários observam outra oportunidade e empreendem a sua busca antes de tentar atuar na área que eles trabalhavam e; iii, os empresários apenas querem mudar a vida e agarram a oportunidade que aparece. Essas alternativas, elaboradas a posteriori, ainda carecem de confirmação.

O fato é que a grande incidência de respostas de atuação em ramos diferentes combinada com a significativa parcela daqueles que declararam não conhecer previamente seus atuais ramos de negócios e mercados (item anterior) sugere decisões muito pouco fundamentadas nos arcabouços acadêmicos da gestão contemporânea.

Cerca de 55\% da amostra das empresas de brasileiros em Orlando começaram a operar apenas com o dono, sem empregados. Na ocasião da enquete, era da ordem de $25 \%$ as empresas que ainda não tinham funcionários. Diante da ausência de dados sobre o volume total de empregos gerados nos EUA pelos negócios brasileiros, este é um dado que permite afirmar, pelo menos, que há sim geração de empregos nos negócios brasileiros. Ainda que a maioria dos empregados dessas empresas também sejam brasileiros, constatamos empregados de origem hispânica, norte-americana e de outras nacionalidades.

"Eu não tenho certeza se as pessoas estão cientes de quão grande e crescente é o papel de alguns imigrantes como donos de empresas", disse David Dyssegaard Kallick, diretor de Pesquisa do Fiscal Policy Institute ao NY Daily News. O fato é que "Os imigrantes estão expandindo a economia" (Raguzo, 2012). 


\section{Sustainable Business International Journal}

JANEIRO DE 2016- ISSN 1807-5908

Conforme aprendemos com Schumpeter (1961), o empreendedor é, sobretudo, um sujeito inovador que impulsiona o desenvolvimento econômico e social por intermédio da reforma ou da revolução nos padrões de produção. Parece que é isso que estamos encontrando entre empreendedores brasileiros na cidade de Orlando.

No campo da Gestão de Pessoas, nenhum dos empresários ouvidos declarou ter parentes em suas empresas; $68 \%$ dos novos funcionários, de acordo com eles, são pessoas desconhecidas. Entretanto, quando interrogados sobre o que é mais importante: ser de confiança ou ter conhecimento do serviço, as respostas foram: $75 \%$ considera que é mais importante ser de confiança; e $25 \%$ considera que é ter conhecimento do serviço.

Essas respostas parecem corresponder a uma sinalização do Instituto Brasileiro de Geografia e Estatística - IBGE (2003) de que as micro e pequenas empresas constituem uma "alternativa para uma grande parcela da força de trabalho excedente, em geral com pouca qualificação". Todavia, um olhar mais etnologicamente treinado sobre a natureza das relações de emprego na sociedade brasileira pode facilmente explicar que a confiança pessoal é fator decisivo para que um patrão brasileiro abrigue empregados sob seu comando, sobretudo em pequenos negócios, onde o olhar do dono é permanente. Afinal, é o olho do dono que faz o boi engordar. ${ }^{4}$ A confiança profissional não é desprezada, porém secundária. Não admira que empresários brasileiros, mesmo na terra da Teoria Geral da Administração, reproduzam o modelo de patronagem de sua herança cultural.

Acerca das expectativas sobre o futuro dos negócios na economia de Orlando, além de um curtíssimo prazo médio esperado (e, em muitos casos já alcançado) para retorno, $75 \%$ dos empresários têm visões otimistas sobre o futuro dos negócios especificamente na cidade de

\footnotetext{
${ }^{4}$ Ditado brasileiro.
} 


\section{Sustainable Business International Journal}

JANEIRO DE 2016- ISSN 1807-5908

Orlando: grande crescimento (54\%), algum crescimento (21\%), estabilidade (18\%) e queda $(4 \%)$.

Uma das características marcantes do empreendedor é o otimismo. É o que sugere Dornellas (2014). De acordo com o autor, esse sentimento faz com que os empreendedores sempre enxerguem o sucesso, em vez de imaginar o fracasso. Além disso, "eles adoram o trabalho que realizam. E é esse amor ao que fazem o principal combustível que os mantém cada vez mais animados e autodeterminados, tornando-os os melhores vendedores de seus produtos e serviços, pois sabem, como ninguém, como fazê-lo”, Dornellas (2014).

No campo das decisões de localização, identificamos os seguintes fatores (permitida a não exclusão de itens):

Tabela 9: Fatores de localização

\begin{tabular}{|l|l|}
\hline Preço do aluguel & $48,15 \%$ \\
\hline Facilidade de acesso dos clientes & $77,78 \%$ \\
\hline Espaço interno da loja & $51,85 \%$ \\
\hline O local é de habitual frequência de clientes & $62,96 \%$ \\
\hline
\end{tabular}

O agrupamento das lojas em diversas cidades dos EUA - em malls (pequenas lojas dispostas em uma espécie de shopping a céu aberto, com estacionamento para clientes) - e a necessidade de se criar clusters destinados a turistas brasileiros favorece muitos grupos de empresários a investirem nesses espaços, transformando-os em pequenas ilhas de negócios brasileiros, embora não formem, necessariamente, uma comunidade de negócios. Este é o caso de Orlando, onde os malls aglomeram padarias, mercados de gêneros de subsistência, restaurantes, agências de viagens, lojas de varejo em perfumaria, eletrônicos, vitaminas, dentre outros. Isso facilita a movimentação dos clientes e gera um clima brasileiro em plenos 


\section{Sustainable Business International Journal}

JANEIRO DE 2016- ISSN 1807-5908

EUA. A maioria dos estabelecimentos comerciais brasileiros está situada em malls ao longo da International Drive.

O critério de precificação de mercadorias a venda predominantemente declarado foi a determinação de preços a partir da fixação de margem de lucro sobre o custo $(54 \%$ das respostas). Os demais respondentes se dividem entre o método de precificação de acordo com a concorrência ou através do valor percebido pelo cliente. É de se notar que uma rápida pesquisa de preços comparados entre as lojas brasileiras e estabelecimentos americanos revelam uma prática de preços mais elevados entre as primeiras, principalmente em itens eletrônicos. Acerca do investimento realizado, 99\% dos entrevistados afirmaram estar satisfeitos com o próprio negócio.

Sobre a relação dos empresários com o turismo brasileiro e com a cidade de Orlando, $56 \%$ dos entrevistados declararam que seus negócios dependem de turistas brasileiros para sobreviver. Porém, $87,5 \%$ deles não mudariam para outra cidade em busca de outros turistas brasileiros e $69 \%$ dos respondentes não mudariam de negócio mesmo que o número de brasileiros diminua na cidade de Orlando. Trata-se de um contrassenso empresarial. As respostas nos fazem retornar aos motivos da internacionalização, em sua maioria pessoais, em detrimento as questões de mercado como expansão de negócios ou oportunidades. Parece que o apego ao País e, em particular, à cidade de Orlando, faz os empresários romperem a racionalidade das decisões econômicas e se apegar a paixões pessoais.

Outro dado obtido reforça esse argumento. Cerca de 56\% dos entrevistados chegaram aos EUA pela cidade de Orlando. Se lembrarmos que muitos dos entrevistados afirmaram ter decido estabelecer negócios após se sentirem encantados com o país, parece que também estão dispostos a arriscar seus negócios para se manter na cidade. Não foram observados 


\section{Sustainable Business International Journal}

JANEIRO DE 2016- ISSN 1807-5908

conflitos ou dificuldades severas de adaptação cultural, nos moldes propostos pelo modelo de Black (1988). Todavia, um aprofundamento da pesquisa através de referenciais etnológicos ainda está em andamento. Para finalizar, $65 \%$ da amostra declararam acompanhar os noticiários brasileiros na televisão, mas $82 \%$ afirmaram que não voltarão mais para ao Brasil e, dos que responderam que voltariam, todos colocaram restrições ou condições (em torno de fatores como segurança, qualidade de vida, educação) ou só voltariam a passeio.

\section{Considerações finais}

Diferentemente do que sugerem os encantadores sorrisos sobre o fundo azulado do mar de Miami Beach nas fotos que ilustram a reportagem intitulada "Viver em Miami" da revista brasileira IstoÉ (2014), a vida da maioria de emigrantes brasileiros nos EUA não é exatamente representada por uma fotografia de agência de turismo. Em nosso trabalho de campo encontramos vários empresários trabalhando 6 ou 7 dias por semana, 10 horas por dia, o ano inteiro, com intervalo de 1 ou 2 semanas de férias. "A vida é dura aqui nos Escravos Unidos!", disseram muitos deles, mas a maioria não quer voltar. A impressão geral que nos tem sido causada é a predominância de um sentimento de recompensa. O trabalho é duro, os impostos não são baixos, mas ver que o resultado do trabalho efetivamente se converte em qualidade de vida causa uma espécie alegria cidadã. A cidade funciona, o trânsito flui, a escola pública ensina, os serviços públicos parecem ser mesmo dotados da propriedade de

servir. É como se o imigrante brasileiro vivesse nas condições que gostaria de viver no Brasil. Para isso, não hesita em investir seus recursos nos negócios em que nem sempre tem experiência, em mercados que nem sempre conhece. 


\section{Sustainable Business International Journal}

JANEIRO DE 2016- ISSN 1807-5908

No entanto, a aparente ausência de racionalidade econômica é causadora de forte impacto econômico. Nas últimas décadas, tanto a literatura técnica em economia e gestão quanto a leiga fizeram parecer que a economia americana é movida apenas pelas grandes corporações, dando a impressão de que não existem pequenos negócios nos EUA. Mas os Estados Unidos da América continuam a ser uma terra de imigrantes que, para sobreviver, encontram no empreendimento pessoal o meio mais viável. O resultado é uma grande economia de pequenos negócios, com impactos consideráveis no produto interno, na empregabilidade e na arrecadação governamental. Não há como não reconhecer esses movimentos como pertencentes a uma certa categoria de Internacionalização de Negócios.

E se tratando do perfil do empresário brasileiro em Orlando, pode-se dizer, com toda certeza que apesar das diferentes origens no Brasil, todos comungam de uma administração intuitiva, com a gestão de pessoas pautada na relação de confiança entre patrões e empregados e, acima de tudo, dependentes dos turistas brasileiros. Claro que foram identificadas exceções, mas o esforço de empreender em um país com burocracia, hábitos de consumo e relações de trabalho bem diferentes do Brasil faz com que muitos empreendedores sigam o caminho da "brasileirização", ou seja, adaptação do modus operandi ao jeito brasileiro de ver as coisas e por que não, de administrar uma empresa. Isso talvez explique o interesse dos homens de negócio por empregados brasileiros, um contador brasileiro e relações com o turista brasileiro. Percebemos uma cadeia de compromissos entre patrões, empregados e clientes que muitas vezes excluem o cidadão americano daquele tipo de negócio. Por exemplo, poucos são os esforços de inserir na cultura americana o hábito de comer um pastel como lanche ou usar um biquíni com cortes brasileiro - mesmo que tenha sido encontrados diversos restaurantes e algumas lojas de moda praia brasileira. 


\section{Sustainable Business International Journal}

JANEIRO DE 2016- ISSN 1807-5908

Habitualmente, voltados para movimentos de internacionalização a partir de uma origem nacional qualquer, os modelos vigentes de empreendedorismo internacional têm focado os investimentos decorrentes da acumulação da riqueza nacional, cuja expressão de pujança se projeta nas exportações de produtos e de habilidades e, por fim, na criação de empregos em economias de destino. Enquanto isso, o imigrante empreendedor cria empregos e paga impostos agora. Dessa forma, trabalhos foram iniciados com o intuito de responder as seguintes hipóteses: é possível enquadrar o modelo de internacionalização identificado em alguma teoria atual que trata do tema? É possível generalizar o movimento de internacionalização experimentado em Orlando em outras cidades dos EUA ou do mundo? Quais os conceitos fundamentais seriam necessários para sedimentar uma teoria híbrida sobre internacionalização de negócios brasileiros? O fenômeno observado decorre apenas de empresários brasileiros ou podemos identificar modelos similares na expansão hispânica ou chinesa? É possível explicar a formação de cluster e o relacionamento através dos modelos de enclave sugeridos, por exemplo, por Portes e Zhou (2012)?

Em um próximo trabalho, alicerçados nos resultados desta pesquisa de campo (da qual ainda não conhecemos par) e em outras fontes, pretendemos avançar na sugestão de um novo modelo de Internacionalização de Negócios que contemple a participação do imigrante empreendedor.

\section{Bibliografia}

Banco Central do Brasil - BACEN. (2014). CBE - Capitais Brasileiros no Exterior. BACEN, Rio de Janeiro.

Barbosa, M. A. 2014. EUA é o país com mais eleitores brasileiros que vivem no exterior. Gazeta Brazilian News, 24 de julho de 2014.

Black, J. S. 1988. Work role transitions: a study of American expatriate managers in Japan. Journal of International Business Studies.19 (2) pp. 277-294.

Coase, R. 1937. The nature of the firm. Economica, v. 4, n. 16, p.386-405.

Crick, D.; Jones M. V. 2000. Small High-Technology Firms and International HighTechnology Markets. Journal of International Marketing. Volume 8, N. 02, p.63-85. 


\section{Sustainable Business \\ International Journal}

Dalmoro, M. 2008. Empreendedorismo internacional: convergência entre o processo de internacionalização da empresa e a atividade empreendedora. Revista FACEF Pesquisa: Desenvolvimento e Gestão v.11, n.1.

Delboni, C.; Barboza, M.Q. 2014. Viver em Miami. Revista Isto É, 01 de novembro de 2014.

Dib, L.A.R. 2008. O processo de internacionalização de pequenas e médias empresas e o fenômeno born global: estudo do setor de software no Brasil. Tese de doutorado. Instituto COPPEAD de Administração, Universidade Federal do Rio de Janeiro.

Dornelas, J. 2014. Empreendedorismo: transformando ideias em negócios - $5^{\mathrm{a}}$ Ed. Rio de Janeiro: LTC.

Dunning, J. 1977. Trade, location of economic activity, and the multinational enterprise: a search for an eclectic approach. In: OHLIN, B. et al (ed.) The international allocation of economic activity. London: Macmillan.

Ellis. P.; Pecotich, A. 2001. Social factors influencing export initiation in small and mediumsize enterprises. Journal of marketing research, Chicago, v.38, n.1, p. 119-130.

Hilal, A.; Hemais, C.A. 2001. Da escola de Uppsala à escola Nórdica de Negócios Internacionais: uma revisão analítica. In: ENCONTRO NACIONAL DOS PROGRAMAS DE PÓS-GRADUAÇÃO EM ADMINISTRAÇÃO, 20, 2001, Campinas. Anais... Rio de Janeiro, ANPAD.

Holland, N. A. 1999. A internacionalização dos negócios. São Paulo: editora Forense.

Hymer, S. 1960. The international operations of national firms: a study of direct investment. Doctorate thesis. Cambridge, MA: The MIT Press.

Instituto Brasileiro de Geografia e Estatística - IBGE. 2003. As Micro e Pequenas Empresas Comerciais e de Serviços no Brasil 2001. Estudos \& Pesquisas Informação Econômica Número 1. Rio de Janeiro.

Instituto Brasileiro de Planejamento Tributário - IBPT. 2012. Empresômetro: censo das empresas e entidades publicas e privadas brasileiras. IBPT: São Paulo.

Johanson, J.; Mattson, L. 1986. International marketing and internationalization processes - a network approach. In: PALIWODA, S.; TURNBULL, P.W. (ed.) Research in international marketing. London: Croom Helm.

Johanson, J.; Vahlne, J. 1977. The internationalization process of the firm: a model of knowledge and increasing foreign market commitment. Journal of International Business Studies, v. 8, n. 1, p. 23-32.

KNIGHT, G. A.; CAVUSGIL, S. T. 2004. Innovation, organizational capabilities, and the born global firm. Journal of International Business Studies, v. 35, p.124-141.

McDougall, P.; Oviatt, B. 1994. Toward a Theory of International New Ventures, Journal of International Business Studies, 24, pp:45-64.

McDougall, P.; Oviatt, B. 2000. International entrepreneurship: the intersection of two research paths, Academy of Management Journal, vol. 43 n..5, pp.902-906.

Murray, V. 2012. List: America's Most-Visited Cities. Forbes, 2012.

Organização para a Cooperação e Desenvolvimento Econômico - OECD. 2002. Frascati Manual: proposed standard practice for surveys on research andexperimental development. Paris: OECD.

Portes, A.; Zhou, M. 1992. "Gaining the Upper Hand: Economic Mobility among Immigrant and Domestic Minorities." Ethnic and Racial Studies 15(4): 491-522.

Raguzo, S. 2012. Imigrantes brasileiros apostam em seu próprio negócio no sul da Flórida. Gazeta Brazilian News, 26 de junho de 2012. 


\section{\begin{tabular}{|c} 
Sustainable Business \\
$\mid$ International Journal
\end{tabular}}

JANEIRO DE 2016- ISSN 1807-5908

República Federativa do Brasil. 2006. Congresso Nacional. Comissão Parlamentar Mista de Inquérito da Emigração. Relatório final da Comissão Parlamentar Mista de Inquérito. Brasília, 2006. Disponível em: em: $\quad<$ http://www.diasmarques.adv.br/artigos/Relatorio_CPI_Emigracao_Ilegal.pdf >. Acesso em: 01 jul. 2012.

Schumpeter, J.A. 1961. Teoria do Desenvolvimento Econômico. Teoria do Desenvolvimento Econômico. Editora Fundo de Cultura, Rio de Janeiro

Serviço Brasileiro de Apoio às Micro e Pequenas Empresas - SEBRAE. 2007. Fatores Condicionantes e Taxas de Sobrevivência e Mortalidade das Micro e Pequenas Empresas no Brasil, 2003-2005. São Paulo: Sebrae. Disponível em:<http://www.biblioteca.sebrae.com.br>. Acesso em 23 de agosto de 2014.

Veja. 1996. A Miami do Brasil: A Flórida é a nova fronteira dos brasileiros, que já são 200.000 e faturam 5 bilhões por ano. Revista Veja, 17/7/1996. 